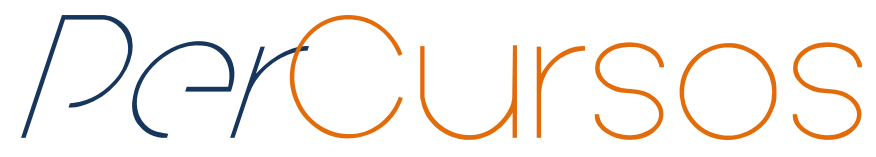

\title{
"Brincadeiras de negros": religiosidade e performance nas práticas do Cacumbi em comunidades afro-brasileiras
}

\begin{abstract}
Resumo
"Brincadeiras de negros" : religiosidade e performance nas práticas do Cacumbi em comunidades afro-brasileiras tem como ponto de partida as poéticas das práticas religiosas dos quintais no contexto moçambicano e afro-brasileiro para pensar uma possível compreensão sobre a arte que emerge dessas práticas. Busco aqui explorar as manifestações do Cacumbi/Catumbi em Santa Catarina. Para comprender como tais manifestações se constituíram, faz-se necessário associá-las ao modo como foram abordadas nos estudos sobre as populações negras em Santa Catarina: sob a mais absoluta invisibilidade dos negros do Sul do Brasil. Leite (1996) chama a atenção para a invisibilidade histórica a que foram submetidas as comunidades negras no estado de Santa Catarina (SC), inclusive no que se refere às suas manifestações socioculturais. Eis, portanto, o imperativo deste trabalho: desvelar a dimensão expressiva do Catumbi, compreendendo-o como prática religiosa afro-brasileira. Os estudos sobre a performance desenvolvidos por Paul Zumthor (2000; 2005) constituem-se como fundamentais para esta discussão, especialmente, por não tratarem a performance como desempenho, mas sim, como recepção: 0 momento em que o enunciado é realmente recebido por intermédio da "voz viva". Ao lado da voz, o autor coloca como fundamentalmente importante a escuta para, a partir dela, instituir a concepção de vocalidade. Como resultado, constatamos que práticas religiosas como o Catumbi tiveram uma grande contribuição na constituição de uma performance negra no Brasil (LIGIÉRO, 2011) não um "folclore negro" como denominado por uma 'ideologia da desqualificação' (LOPES, 2011) das práticas afro-brasileiras.
\end{abstract}

Palavras-chave: Cacumbi/Catumbi. Religiosidade Afro-Brasileira. Performance Negra. Vocalidade.

ra. Vocalidade.

\author{
Roselete Fagundes de Aviz \\ Doutora em Educação pela \\ Universidade Federal de Santa \\ Catarina - UFSC. \\ Brasil \\ roseaviz@yahoo.com.br
}

\footnotetext{
Para citar este artigo:

AVIZ, Roselete Fagundes de. "Brincadeiras de negros": religiosidade e performance nas práticas do Cacumbi em comunidades afro-brasileiras. Revista PerCursos, Florianópolis, v. 19, n.39, p. 128 - 153, jan./abr. 2018.
}

DOI: 10.5965/1984724619392018128

http://dx.doi.org/10.5965/1984724619392018128 


\title{
"Black people jokes": religiosity and performance in the practices of the Cacumbi in Afro-Brazilian communities
}

\begin{abstract}
"Black poeple jokes": Religiosity and performance in the practices of the CACUMBI in Afro communities of Santa Catarina has as a starting point the poetics of the religious practices of the Quintas in the Mozambican and AfroBrazilian contexts to think a possible understanding about art emerging from these practices. Here I seek to explore the manifestations of the Catumbi/Cacumbi in Santa Catarina. To understand how such manifestations were constituted, it is necessary to associate them with the way they were addressed in the studies on the black populations in Santa Catarina: in the most absolute invisibility of the black people in southern Brazil. Leite (1986), draws attention to the historical invisibility to which were subjected the black communities in the state of Santa Catarina (SC), including what refers to their sociocultural manifestations. This is therefore the imperative of this work: to reveal the expressive dimension of the Catumbi, understanding it as a Afro-Brazilian religious practice. Studies on a performance developed by Paul Zumthor (2000; 2005) constitute as fundamental for this discussion, especially, because I do not mean performance as performance, but rather, as a reception: the moment when the enunciation is actually received through "live voice". Beside the voice, the author places as fundamentally important listening, to institute from it a conception of vocality. As a result, we found that religious practices such as Catumbi had a major contribution in the constitution of a black performance in Brazil (LIGIÉRO, 2011) and not a "black folklore” as a 'ideology of disqualification' (Lopes, 2011) of the Afro-Brazilian practices Afro-Brazilian.
\end{abstract}

Keywords: Cacumbi/Catumbi. Afro-Brazilian Religiosity. Black Performance. Vocality. 
Foi lindo o encontro, as almas ficaram alegres. ${ }^{1}$

\section{Introdução}

As reflexões a que este texto convida têm origem no desdobramento (AVIZ, 2012) e aprofundamento (AVIZ, 2016) de uma investigação sobre a voz/escuta como devir: movimento que no processo de pesquisa se mostra em presença, som, silêncio, música, testemunho, transmissão e memória. O resultado constitui uma reflexão sobre a viagem como um significativo elemento de formação. O trabalho teve como corpus os fragmentos de diários de campo, os quais denominei Cadernos de Viagem que se concretizam pela escrita tornada voz no rastro traçado durante todo o trajeto da pesquisa.

O recorte selecionado para este trabalho tem como foco a dimensão expressiva do Catumbi, compreendendo-o como prática religiosa afro-brasileira, tendo como ponto de partida o encontro com homens, mulheres e crianças rongas ou changanas ${ }^{2}$ em alguns quintais de Moçambique. Foi vivendo com eles, partilhando seu cotidiano, ouvindo e aprendendo a sentir o seu modo de estar no mundo que construí uma trilha possível para melhor refletir, neste texto, sobre a prática religiosa afro-brasileira Cacumbi/Catumbi em Santa Catarina.

Paul Zumthor se constitui como um importante participante deste diálogo porque concebe a performance não somente como representação cênica, mas como o momento em que o enunciado é realmente recebido. E esse enunciado tem como seu principal elemento a poesia: "uma pulsão do ser da linguagem" que só pode existir na "voz viva" na qual “o pensamento é cantado”. Assim, para Zumthor (2005, p. 83) “a voz é presença. Isso explica porque a performance não pode ser outra coisa senão presente". Ao lado da voz, o autor coloca como elemento principal a escuta. Nesse sentido, mais do que uma

\footnotetext{
${ }^{1}$ NGWENYA, Malangatana (2010).

${ }^{2}$ A língua changana pertence ao grupo tshwa-ronga. Esse grupo é designado pelo termo tsonga. As três línguas são mutuamente inteligíveis. O changana é falado em Moçambique nas províncias de Maputo, Gaza e parte de Inhambane, Manica e Sofala. É ainda falado na África do Sul e no Zimbábue. Cf. BENTO SITOE, Dicionário changana-português, Maputo: Instituto Nacional do Desenvolvimento da Educação, 1996.
} 
prática da oralidade (tradição oral), práticas como o Catumbi poderiam ser pensadas como vocalidade: aspectos da emoção que envolvem a plena corporeidade dos participantes ${ }^{3}$. A partir das melodias cantadas para cada momento, sem resumir nenhuma história, os participantes estão falando do contexto de suas vidas. No entanto, o significado dessa história não está relacionado ao conteúdo, mas ao tempo, à repetição, às formas de vida, tudo isso, modos de escuta. É olhando nessa direção que Henri Meschonnich (2006, p. 51), argumenta que o lugar onde a escuta se da é no ritmo. Assim, defendo que na performance da poética da religiosidade dos quintais há a possibilidade de diálogo com o passado, a transmissão de experiência memorial, de um saber ancestral, anterior, cuja concretização se dá primeiramente na voz como canção.

Fazer esta reflexão a partir da sabedoria coletiva, fora do estar que a todos é comum, já que parte do contexto moçambicano, é observar a realidade sob outra ótica, deslocada dos limites dos modelos e conceitos próprios da cultura europeia.

Assim, tomo como ponto de partida as poéticas da religiosidade dos quintais no contexto moçambicano. Especialmente, no desenrolar de um encontro do artista Malangatana Ngwenya e a intimidade de sua família, no sentido de compreender o significado de “contar histórias", no contexto dos rongas ou changanas de Moçambique, uma vez que, nenhuma história pode estar separada do contexto de suas vidas e uma cerimônia para dar nome a uma criança: o kenguelequezêt $\hat{e}^{4}$, reproduzindo em alguns fragmentos a complexidade do contexto em que acontecem para compor uma imagem da maneira de estar e do modo como os rongas e changanas integram o mundo dos vivos com o mundo dos mortos. E ainda, para poder fazer outras perguntas sobre práticas afrobrasileiras como o Cacumbi/Catumbi e, assim, pensá-las para além do embate entre o

\footnotetext{
${ }^{3}$ ZUMTHOR, 2005, p.141

${ }^{4}$ Kenguelekezê é uma expressão proferida (na verdade, gritada) nesse tipo de cerimônia enquanto alguém que segura o bebê o balança e lhe mostra a Lua. Na realidade, é uma dupla apresentação: apresenta-se o bebê à Lua e, ao mesmo tempo, a Lua ao bebê. Nas tradições bantu acredita-se que muitas doenças que atacam os recém-nascidos têm a ver com esse astro, inclusive uma conhecida como doença da lua, que se manifesta como uma epilepsia. Durante a cerimônia de dar nome ou de "tirar o bebê" (que geralmente coincidem), tirar bebê significa: apresentação do bebê, geralmente um mês após o nascimento kenguelequezê. Nesta ocasião, deve-se mostrar o bebê à Lua para que ela seja mais piedosa e generosa, e assim ele cresça com saúde. Esses hábitos tendem a desaparecer sobretudo nas cidades, onde os jovens já dão nome aos filhos sem nenhuma cerimônia - em geral, são escolhidos antes mesmo do nascimento. Mas no campo, ainda se faz todo o ritual; mesmo quando o bebê sai da maternidade, caso tenha nascido na cidade, fica sem nome e aguarda essa cerimônia para recebê-lo.
} 
catolicismo e as religiões afro-brasileiras ou ainda como registro folclórico, conforme aparece em alguns documentos que temos sobre essa prática no referido estado.

O convite, então, é para alargar a percepção a partir das cenas dos quintais Moçambique-Brasil começando por alguns pontos que serviram para a análise, dentre eles: voz, escuta, vocalidade, religiosidade, performance, pertencimento, conduta, existência, memória e alteridade. Neste sentido, peço licença para trazer essas cenas construídas a partir de alguns fragmentos dos meus Cadernos de Viagem, na expectativa de que a narrativa desenhe uma imagem que sirva de abertura para discussão sobre o tema aqui proposto e, com base nessas problematizações, abrir o debate para outras pesquisas que possam pensar sobre "religiosidade e performance no Cacumbi em comunidades afro-brasileiras de Santa Catariana."

\section{Parte 1: A poética da religiosidade dos quintais}

$$
1^{a} \text { Cena }^{5}
$$

É noite. No quintal, a fogueira foi acesa cuidadosamente. Malangatana Ngwenya ${ }^{6}$, o mais velho e respeitado da família chega e se acomoda. As crianças olham com atenção e curiosidade para cada performance. A noite para elas é de escuta. É momento de aprenderem com os mais velhos quem elas são. Um dos anciãos cuida do amendoim que está sendo torrado na fogueira. Quando está no ponto, é colocado na palha do milho. Malangatana pega sua parte e vai de pessoa em pessoa na roda compartilhar o alimento. Ao mesmo tempo, aproveita para reconhecê-las. As pessoas de quem se lembra, chama pelo nome e apresenta alguma lembrança de suas vidas. Aos que não reconhece, pergunta “Quem és tu?". Quando isso acontece, a família o apresenta lembrando-o dos pais: "Esta é a filha de Azarias". Só quando chega à última pessoa é que retorna ao seu lugar. E, então, a história acontece. Um a um, cada familiar vai ao centro da roda para

\footnotetext{
${ }^{5}$ Cena transcrita do filme Ngwenya, o Crocodilo, da moçambicana Isabel Noronha.

${ }^{6}$ Considerado o maior artista plástico do continente africano. Sua projeção em África e fora dela se fez notável: África do Sul, Nigéria, Portugal, Brasil, Londres, dentre outros. Além de pintor, foi poeta, músico, ator, escultor, enfim, um homem de várias qualidades e virtudes. Malangatana faleceu em 5 de janeiro de 2011, em Portugal, para onde viajara a trabalho. Nos murais da vida, sua voz ecoará sempre.
} 
contar alguma história que envolva o tão querido visitante: Malangatana. As histórias não são fictícias: “Aqui nesta fogueira, por tradição, contam-se histórias que falam da forma de pensar das pessoas e das suas vidas, como é o caso do Malangatana", diz o primeiro contador. O segundo dá um giro e pergunta às pessoas da roda: "Vocês sabem de onde vem a família Ngwenya?". Algumas respondem: “sabemos que vem de um rio”. "Os Ngwenya” - ele diz, pausadamente - "vêm de longe, lá de Ussapa. Antigamente, as grandes cerimônias eram preparadas pela família Ngwenya. Quando chegaram a esta linda terra, viram que tinha boas condições e fixaram-se aqui. Não sei por que tem esse nome. Talvez porque fossem comedores de crocodilos". Assim que se cala e retorna ao seu lugar, uma voz feminina ressoa: “Karingana Wa Karingana”. E todos respondem: “Karingana". "Karingana Wa Karingana", ela repete. E a resposta novamente é “Karingana”. “Em primeiro lugar, quero saudar Malangatana: Olá Malangatana!”. E Malangatana responde: “Kanimambo!”. “Meu irmão”, ela replica. Depois, continua sua narrativa. “Meu nome é Percina Ngwenya, filha do Chikwa Ngwenya, tio de Malangatana. O meu nome de criança é Nhancuave [...]”. Os panos com que as mulheres se vestem são as capulanas ${ }^{7}$. Este momento é um dos momentos do "lembrar-te". Referências pessoais do familiar visitante: Malangatana, reverberam em sensações musicais que a língua ronga expressa. Falam ora em palavras, ora em gesto de cor, através das capulanas, bem como no cheiro ou sabores dos grãos que saem da fogueira e alimentam a roda. Nas cenas observadas, há um discurso que se dá entre os corpos em movimento. Uma aprendizagem que se estabelece na interação dos corpos, no som de palavras às vezes incompreensíveis, no movimento de suas vozes. Fixo minha atenção em todos esses elementos que materializam sentidos. Chama atenção a brincadeira em roda. Destaca-se o ritual em todo o seu movimento. O que me leva a pensar no lugar da voz no canto do povo de um lugar (Moçambique). No canto de uma palavra africana.

\footnotetext{
7 Vestuário tradicional das mulheres moçambicanas. Em geral, são confeccionados com tecidos coloridos e estampados. Foram trazidos ao continente africano no século XIX por mercadores que vinham do Oriente.
} 


$$
2^{a} \text { Cena }
$$

Agora, o cenário é outro quintal. É dia de domingo. Dia de celebração. Dia de kenguelekezê - cerimônia para dar nome ao bebê, dia de dar nome a uma linda menina, filha de Safi, que nasceu há um mês e meio. Dessa vez, a canção está presente:

Hitlangela xin'wanana xingapsaliwa namuntlha (repetem três vezes)

[Agraciamos/felicitamos o bebê que hoje nasceu]

Ambuwetela ambuwetela, ambuwetela

[Anina, anina, anina o bebê]

Mamani wa kona ambuwetela ambuwetela, ambuwetela

[A mãe do bebê anina, anina, anina o bebê]

Papayi wa kona ambuwetela ambuwetela, ambuwetela

[O pai do bebê anina, anina, anina o bebê]

Titiya wa kona ambuwetela ambuwetela, ambuwetela

[A tia do bebê anina, anina, anina o bebê]

Vovote wa kona ambuwetela ambuwetela, xingapsaliwa namuntlha

[A avó do bebê anina, anina, anina o bebê] $]^{8}$

Homens e mulheres cantam acompanhados de palmas, pés e jogos com o corpo, além dos sonoros uncunlunguanu ${ }^{9}$ das mulheres. Depois volta o silêncio. Mulheres nas esteiras e homens nas cadeiras confidenciam histórias. As mulheres em volta de Safi ouvem-na contar que o parto da filha não foi difícil. Dessa vez, não foi pelas mãos de sua tia, a maior especialista em partos e doenças de crianças, que a filha veio ao mundo. Além de a tia já ser falecida, Safi mora na cidade, por isso o parto não foi em casa. E, não fosse essa tia, muitos dos presentes certamente não teriam o privilégio de crescer. A avó de Safi, ao tomar a palavra, fala ainda com maior segurança sobre a filha parteira. Ela conta dos vários amuletos que preveniam contra os males, em especial os próprios para recémnascidos, os mais indefesos. A avó conta que ninguém se arriscava a deixar seu bebê sem determinada imunidade, feita muitas vezes de planta ou do animal que tinha a força que se pretende transmitir, como forma de vaciná-lo. E é assim que, nesse dia, as mulheres velhas, no seu canto, também falam dela. É assim que o segundo nome da bebê a unirá

\footnotetext{
${ }^{8}$ Esta canção, "Xin’wanani”, é específica para a ocasião de partos tradicionais, ou seja, que não são realizados na maternidade, mas pelas anciãs da comunidade, com experiência no assunto. A canção é bastante cantada também nas cerimônias de "tirar o bebê" e nas de kenguelequezê.

${ }^{9}$ Uma espécie de som vocal emitido pelas mulheres, especialmente com a língua.
} 
para sempre à falecida representada. Desse modo, mais do que uma homenagem, isso representa a encarnação desse parente falecido.

Ao encerrar a fala, a avó vai devagarinho pondo-se em movimento e começa a entoar outra canção. Não demora muito e todas as mulheres a acompanham:

Vanavela va kuchava kuveleka vanavela!

[Os que têm medo de ter filhos cobiçam!]

Va kuchava kuveleka! (repete-se o verso várias vezes)

Ampfilwa lowu hi lowu wopsala sviyukuku

[Esta mpfilwa ${ }^{10}$ é aquela que dá bons frutos]

Aloko anini male anitophindha kambe!

[Se tivesse dinheiro repetia de novo!]

Phindha kambe!

[Repetia de novo! $]^{11}$

No contexto dos quintais, o canto não é instrumento musical simples. Cantar é também comunicar-se, é religar-se à ancestralidade. Em uma roda brincante de vozes que afetam o imaginário de todos os participantes, escuto vozes que mostram o quanto 0 canto e a dança fazem parte do imaginário desse lugar. As canções dos quintais são trazidas dos guardados da memória e apresentadas em performance.

\section{$3^{a}$ Cena}

Lá pelos anos de 1940, na localidade de Cachoeira, Biguaçu (SC) ${ }^{12}$, onde meu pai nasceu, a família se reunia sempre no quintal para celebrar. Meu tio Francisco assim me contou:

\footnotetext{
${ }^{10}$ Árvore frutífera cujos frutos são mapfilwa. Em português poderia corresponder à figueira.

11 "Vanavela va kuchava kuveleka", canção tradicional "cantada geralmente nas cerimônias de kuhumesa n'wana = tirar a criança: tirar bebê recém-nascido (apresentação do bebê, geralmente um mês após o nascimento), kenguelequezê, lobolo, casamento ou em qualquer cerimônia em que os pais sentem-se felizes e orgulhosos por algo de positivo que os filhos tenham feito. A minha avó entoa essa canção sempre que eu the dou alguma coisa, seja capulana, roupa, dinheiro etc., é como se dissesse: 'eu tenho isto porque tive filhos, e os que não têm cobiçam"' (depoimento de Ezra Chambal, caderno de viagem, 2 out. 2010).

${ }^{12}$ Há referência a um grupo de cacumbi registrado pelo pesquisador Walter Piazza, no interior de Biguaçu, na localidade de Cachoeira, onde havia um reduto de negros. Segundo o pesquisador, a discriminação racial se manifestava pela existência de bailes de negros e bailes de brancos, o que incentivaria o "quicumbi" nessa localidade. Na época, só havia um grupo de 13 elementos no quicumbi, e já faria mais de
} 
Eram treze homens: nosso avô, o papai, nossos primos e nós. Seis de um lado e seis do outro, e o vovô Domingos ${ }^{13}$, que era o capitão. O papai, eu e o teu pai tocávamos tambor, mas era pra ter mais, só que quase não tinha mais família. A minha avó sempre dizia que era pra coroar, pra coroar alguém, agora eu já não me lembro mais, mas lembro que ela falava isso ${ }^{14}$.

O Cacumbi, para a família, além de fazer parte da sua crença, é um momento especial em família. É também luta. Luta ao som dos instrumentos musicais. Sons que dominavam o jogo. E o jogo era ter a posse do próprio corpo. Luta porque só uma pessoa em estado de adoração podia brincar durante dias e dias com os pés, as mãos e todo o corpo em completa harmonia com as vozes das pessoas, dos tempos, de outros, e de tudo o que estava à volta: "O vovô Domingos era muito bom no Cacumbi, ele desafiava os mais novo, sabe? Ele era tão rápido! Ficava com a espada, e a pessoa tinha que se defender tocando o pandeiro" 15 . A brincadeira exigia atenção aos gestos, a notação dos passos a serem reexecutados. "E a espada era grande e toda de prata mesmo, menina! Até hoje não sei onde ela foi parar" ${ }^{״ 16}$. Meu pai, quando me contou, soltou faísca dos olhos. Tio Francisco chorou quando disse: “Muitas pessoas recebiam os espíritos dos antepassados no meio da brincadeira, sabe? Um dia, veio meu avô, vovô Domingos, eu sabia que era ele, já havia morrido, mas eu reconheci a sua voz no meio da roda”.

\section{Catumbi}

Na língua tupi, caá + tumbi significa folha (ou mato) azul. No dicionário Houaiss, temos ainda outras interpretações para esse termo indígena: "ao pé do monte" ou “ à

cinquenta anos que não havia reis, rainhas nem juízes. Cf. Jucélia M. Alves, Rose M. Lima e Cleidi Albuquerque (orgs.), Cacumbi: um aspecto da cultura negra em Santa Catarina, Florianópolis: Ed. UFSC/Secretaria da Cultura e do Esporte, 1990, p. 33-4.

${ }^{13}$ Domingos Generosa foi um dos importantes mestres de Cacumbi na região de Cachoeira - Biguaçu no final do século XIX e início do XX. Sobre este aspecto, consultar: SILVA, Jaime José dos Santos. Memórias do Cacumbi: Cultura afro-brasileira em Santa Catarina, século XIX e XX. Dissertação de Mestrado. Florianópolis: UFSC, 2015.

${ }^{14}$ Caderno de viagem 3. Depoimento de Francisco Agostinho de Aviz, o “tio Chico”, 13 jan. 2011.

${ }^{15}$ Ibidem.

${ }^{16}$ Ibidem. 
beira da mata”. Nei Lopes $(2004,2011)$, estudioso e militante da causa negra no Brasil, traz significativas contribuições no sentido de tornar visível a herança africana na sociedade brasileira. É ele quem fica atento à semelhança do termo com o vocábulo bantu "cucumbi". Na etimologia da palavra “cucumbi”, está kikumbi: "puberdade”, "festa da puberdade", além de ligar-se a um rito propiciatório de bom parto, todas práticas muito comuns na maioria dos países africanos, até mesmo em Moçambique.

O mesmo autor, ao citar a obra de Mello Morais Filho (1946), Festas e tradições populares do Brasil, dá atenção aos cucumbis realizados no Rio de Janeiro imperial e afirma que essa era a denominação dada na Bahia às "hordas dos negros de várias tribos", que se organizavam em "ranchos" ou "quintais" de canto e dança na ocasião do Carnaval e do Natal. Nas demais províncias, eles recebiam o nome de "congos". Lopes ainda argumenta que o historiador Morais Filho é quem apresenta o folguedo como representação do cortejo dos negros congos para a apresentação do mameto (criança) recém-circuncidado à sua rainha. O mameto é um "personagem dos antigos cucumbis do Rio de Janeiro que representava uma criança, o filho do rei $^{17}$. Esse vocábulo origina-se do quimbundo mam'etu, interjeição, “ai mamãe!”. A apresentação dos mametos à rainha acontecia sempre "após a refeição lauta do cucumbe", comida de que se serviam congos e munhambanas no dia da circuncisão de seus filhos.

\section{Breve apresentação do Quicumbi/ Cacumbi/ Catumbi ${ }^{18}$ em Santa Catarina}

O Cacumbi é uma manifestação que esteve presente nas festas em homenagem a Nossa Senhora do Rosário em muitas regiões do Brasil, desde o século XVIII. Tal manifestação está estritamente relacionada à história da escravidão no Brasil. Segundo Silva (2015), estas celebrações não existiam ao acaso, elas remetem ao fenômeno mais

\footnotetext{
17 Mello Morais Filho (2002) considera que, até a década de 1830, no Rio de Janeiro, os cucumbis incorporavam os cortejos fúnebres dos filhos de reis africanos falecidos. Segundo este autor: "e precedendo a rede funerária coberta com um pano preto, acercada e seguida de centenas de escravos, os cucumbis marchavam chocalhando e cantando, como seus memêtos (crianças), de cocares de plumas, pulando e levantando os braços, ao compasso acertado" (2002, p. 142).

${ }^{18}$ Essas são as diferentes denominações encontradas para a prática em Santa Catarina.
} 
complexo ao qual necessitamos prestar atenção: a devoção e coroações de reis negros, do contexto da diáspora africana para as Américas.

Em Santa Catarina, a prática era realizada, desde a época da escravidão, por africanos e afrodescendentes e acontecia junto à festa de Nossa Senhora do Rosário e São Benedito. Embora já tivéssemos registros sobre essa prática por alguns folcloristas e estudiosos da cultura popular em Santa Catarina, alguns trabalhos recentes se constituem como fundamentais referências para compreender tal prática para além dessas caracterizações e colocá-la como uma manifestação desenvolvida em determinado contexto histórico, cultural e social. Os trabalhos dos historiadores Jaime José Santos da Silva (2015) e de José Bento Rosa da Silva (1994) são dois dos quais considero muito importantes para os estudos e conhecimento sobre o Cacumbi/Catumbi e devoção a Nossa Senhora do Rosário e São Benedito.

No Cacumbi/Catumbi de Santa Catarina, uma das representações sacras mais importantes é a figura de Nossa Senhora do Rosário. Segundo Marina de Mello e Souza (2012), a consagração à santa teve origem na Europa, mas entre os negros escravizados no Brasil, ela teria recebido novas significações. Segundo o mestre Maia (2011) - CatumbiItapocu -, entre os negros e praticantes do Catumbi reconta-se a história da imagem da santa que teria surgido no meio das águas do mar. Dois escravos fugitivos lhe teriam pedido proteção: “eles tinham fugido porque queriam chegar até um refúgio de negros e foi assim que ela apareceu e ajudou eles." ${ }^{\prime 19}$

A performance do Cacumbi/Catumbi ${ }^{20}$ procura, de certa forma, reproduzir um ritual mítico, por meio de cânticos e diferentes instrumentos musicais, com celebração à santa na Igreja Católica, além da coroação do rei e da rainha. No cortejo, os praticantes, normalmente, estão relacionados a famílias inteiras, ligadas ao catolicismo. ${ }^{21}$

\footnotetext{
${ }^{19}$ Caderno de Viagem 4: Depoimento de Sr. Maia, mestre do Catumbi-Itapocu. Joinville, janeiro de 2012.

${ }^{20}$ Em Santa Catarina a única prática de Cacumbi/Catumbi que ainda atua é a de Itapocu, bastante diferente de algumas práticas como a de Cachoeira, por exemplo, cujos registros escritos e orais apontam diferenças bem específicas.

${ }^{21}$ Pelos registros históricos e história oral, há diferentes versões do Quicumbi/Cacumbi/Catumbi em Santa Catarina. O único que ainda está ativo é o Catumbi de Itapocu, este, por sua vez, pode-se dizer que está integrado ao catolicismo.
} 


\section{Cacumbi: vontade de saber ${ }^{22}$ em torno da intimidade da família}

A epígrafe que abre este texto sintetiza a questão em pauta, remetendo-nos à problemática da compreensão da religiosidade implícita em práticas afro-brasileiras como o Cacumbi. Os versos de Malangatana Ngwenya nos remetem a algumas especificidades implícitas nas práticas dos quintais moçambicanos, que anunciam, em alguns aspectos, semelhanças com práticas dos quintais afro-brasileiros como o Catumbi.

Malangatana Ngwenya sempre dizia "somos comandados a distância. E essas vozes que se manifestam, se apresentam na intimidade do contexto de cada família"23. Tal aspecto pode ser melhor observado naquelas circunstâncias quando percebemos que se inicia com uma representação significativa da celebração do nascimento de uma criança, momento sagrado naqueles quintais, depois, no momento da "Roda das Histórias" cujo sentido, especialmente no contexto dos rongas, acontece na intimidade das famílias e tem como fio condutor as histórias de vida. Esta, a meu ver, é uma questão fundamental quando falamos sobre as práticas afro-brasileiras, em especial à prática do Cacumbi em Santa Catarina.

Antes de qualquer folclorização ou embate com a devoção católica, é importante observar a relação que essa prática tinha com especificidades do continente africano, especialmente: o significado do nascimento de uma criança, a importância das histórias de suas famílias, bem como a veneração aos antepassados. Relembremos o que subjaz à palavra Cacumbi/kikumbi: "rito propiciatório de bom parto". A batida do tambor se constitui como instrumento essencial para este momento por promover a (re)ligação entre o mundo dos vivos e o dos ancestrais.

Considerando que, nas últimas décadas, no Brasil, tem-se despertado para os estudos de práticas tornadas invisíveis pela construção da história oficial do país, pode ser relevante pensar em aproximações entre quintais de lá e de cá para podermos ver melhor a constituição de nossa história e cultura. Tais estudos não podem ser analisados ao

\footnotetext{
22 "Vontade de saber", Categoria referência de Michel Foucault filósofo e historiador francês (1922-1984). Seu nome exerceu grande influência sobre as gerações pós-68. É autor de obras como A História da Loucura, As Palavras e as Coisas, História da Sexualidade, Vigiar e Punir. Suas reflexões de maior importância são sobre o saber, o poder e o sujeito.

${ }^{23}$ Cadernos de Viagem 3. Relatos de Malangatana Ngwenya. Maputo, Moçambique, 2010.
} 
acaso. Verificar práticas como o Cacumbi é como espiar por gretas para o estudo de uma sociedade, de modo que se descubram múltiplos significados para aqueles que participavam dela e também para aqueles que a observavam.

Práticas afro-brasileiras como o Cacumbi e as demais congadas são exemplos necessários para pensarmos em termos de embate entre o catolicismo e as religiões de matriz africana, mas também para além desse aspecto específico. Neste sentido, faz-se necessário reconhecer os homens e mulheres que realizavam essas celebrações como indivíduos conscientes, portadores de histórias e identidades próprias, que deixaram seu legado à formação de uma consciência afro-brasileira, sem rejeitar as tradições africanas em favor das europeias. Assim sendo, neste texto, defendo o Cacumbi como religião e, em assim sendo, peço um silêncio para analisar, para além do que é praticado em público, percebendo as intimidades dos quintais.

É nesse contexto que questionamos o "folclore negro" em defesa de uma "performance negra" muitas vezes não compreendida como tal, porque quase sempre olhamos para práticas como o Cacumbi/Catumbi sob a perspectiva ocidental. Por essa razão, este texto não somente fala por si só como também respalda as aproximações entre Brasil e Moçambique no que tange a algumas especificidades dos sentidos que algumas práticas culturais podem ser interpretadas, especialmente no contexto das famílias e comunidade e dos significados religiosos que não foram possíveis de apagar, mesmo no contexto da não aceitação do outro como protagonista, procedimento próprio das colonizações ${ }^{24}$.

É necessário ressaltar aqui que, embora compreenda que há uma forte relação entre quintais africanos e os quintais afro-brasileiros, considero também que existem diferenças produzidas pela trajetória histórica desses dois espaços culturais. Nos quintais brasileiros, a diferença fundamental se relaciona à presença da escravidão, que impõe a

\footnotetext{
${ }^{24} \mathrm{O}$ intelectual português Boaventura de Sousa Santos tem produzido uma rigorosa reflexão sobre as relações sociais, culturais e econômicas que se estabeleceram em torno dos mecanismos de colonização que se constituíram com o advento das globalizações levadas a efeito pelo o que ele alcunha como "Projeto da Modernidade". Toda a sua obra projeta uma extensa análise deste assunto, inclusive com a produção de intelectuais oriundos do "Sul". Aqui, neste texto, nos interessa em particular os conceitos de "Pensamento Abissal", "Ecologia de Saberes" e proposta de ampliação do cânone do reconhecimento, da diferença e da igualdade.
} 
tensão entre a cultura dos colonizadores e as culturas africanas quando afetadas pela diáspora imposta pelos senhores brancos na partilha de escravos chegados ao Brasil, ao espalhar famílias e grupos étnicos com o intuito de evitar qualquer fortalecimento entre aquelas culturas. São essas características presentes nos quintais afro-brasileiros que produziram diferenças que não podem ser ignoradas. No entanto, para uma reflexão de práticas como o Cacumbi/Catumbi no contexto catarinense que vá além do embate entre o catolicismo e as religiões afro-brasileiras, ou ainda do reducionismo à folclorização, neste texto, tento aproximar características que considero semelhantes entre esses "quintais" para ressaltar seu aspecto de religiosidade e performance preservado, especialmente, na prática do Cacumbi/Catumbi em Santa Catarina, aspectos que muitas vezes se escondem nas falas de quem a vivenciou em seu próprio corpo e que são fundamentais para os debates da história social e da cultura.

Ao colocar o depoimento de Francisco ( $3^{a}$ Cena deste texto) ao lado dos relatos acima, é importante considerar em seus discursos, em alguns momentos, referência à avó: “A minha avó sempre dizia”. Em um dos depoimentos, explica que era da mãe de seu avô que sempre fora advertido, em relação ao Cacumbi como ação de brincar: "é brincar de Quicumbi/Cacumbi ${ }^{25}$ ", ao contrário da maioria dos registros que se referem à prática como dançar Quicumbi/Cacumbi. Em seu depoimento, Francisco, cada vez que nos referimos ao Cacumbi como dança, nos corrige: “dançar não, brincar de Cacumbi”, relembrando dos ensinamentos dos avós.

Lupi $^{26}$ ao saber de tal referência ao Cacumbi explica:

Há uma diferença que quem não conhece não entende. Na religião, o africano é capaz de brincar a sério porque encara a brincadeira como uma coisa séria. Enquanto que os Ocidentais encaram a brincadeira como uma coisa de criança, não é sério, não é de adulto. Agora o africano não, para o africano o brincar é uma coisa séria. Tanto que o famoso Exu que os missionários identificaram como Demônio, Diabo, não é de jeito nenhum, é um Deus que brinca, só que na mente ocidental cristã, um Deus que brinca é inconcebível!

\footnotetext{
${ }^{25}$ Caderno de Viagem 3. Relato de Francisco Agostinho de Aviz:tio Chico, em 13 de janeiro de 2011, Joinville.

${ }^{26}$ Caderno de Viagem 3. Entrevista com o professor e pesquisador João Lupi, em 15 de junho de 2011, Florianópolis.
} 
Capitão Amaro, em muitos momentos em seus relatos, também faz referência ao Cacumbi como brincadeira. Talvez seja importante lembrar que este brincante também iniciou sua vida no Cacumbi em Biguaçu $-\mathrm{SC}^{27}$.

Há no Cacumbi uma forte hierarquia, sendo o capitão o responsável por entoar os cânticos e guardar conhecimentos, toadas e os procedimentos ritualísticos. Tais considerações mostram que, dentro do ritual do Cacumbi, canto e batuque são elementos fundamentais aos aspectos primordiais das religiões africanas - a reverência e invocação aos ancestrais - conforme verificamos, anteriormente, em um dos depoimentos da $3^{\underline{a}}$ Cena: "Muitas pessoas recebiam os espíritos dos antepassados no meio da brincadeira, sabe? Um dia, veio meu avô, vovô Domingos, eu sabia que era ele, já havia morrido, mas eu reconheci sua voz no meio da roda". ${ }^{28}$ Quantas perguntas depoimentos como este podem nos provocar? Em que momento tais manifestações aconteciam, seriam nas noites de pagamento de promessa? ${ }^{29}$ Nesse sentido, as palavras de Silva (2015, p. 125) nos provocam muitos sentimentos: “A folia era religião, não significava folclore". Assim sendo, chamo a atenção para o que Malangatana Ngwenya dizia ao se preocupar com a tendência à folclorização de algumas práticas em Moçambique: “O que os festivais estão a fazer, retalham, sem cerimônias, sem tabus, sem segredo, sem proibição aquilo que era a vida das pessoas numa vida tradicional" 30 e coloco sua fala ao lado do que disse capitão Amaro: "Cacumbi? Cacumbi é cheio mistérios" 31 .

\footnotetext{
${ }^{27}$ Para ler depoimentos completos consultar: SILVA, Jaime José dos Santos. Memórias do Cacumbi: Cultura afro-brasileira em Santa Catarina, século XIX e XX. Dissertação de Mestrado. Florianópolis: UFSC, 2015.

${ }^{28}$ Caderno de Viagem 3. Relato de Francisco Agostinho de Aviz: tio Chico, em 13 de janeiro de 2011, Joinville.

${ }^{29}$ O pagamento de promessa também está ligado à prática do Cacumbi em Santa Catarina. Sobre esse aspecto, Luciana Prass apresenta um importante estudo, em sua obra "Moçambiques, Quicumbis e Ensaios de Promessa..." (2013). Embora seus estudos não sejam referentes à Santa Catarina, suas pesquisas também foram realizadas no sul do Brasil.

${ }^{30}$ Fragmento retirado da minha tese de doutorado, op. cit.

${ }^{31}$ Depoimento de Capitão amaro. In: SILVA, Jaime José dos Santos.
} 
Entro nessa matéria pela evocação de uma lembrança que não apenas me é cara, mas que está profundamente inscrita em mim, e permaneceu subjacente a tudo o que eu ensinei nos últimos quinze anos. Isto tem a ver com minha infância parisiense, as idas e vindas entre o subúrbio em que habitavam meus pais e o colégio do nono distrito onde, no começo dos anos 30, eu fazia meus estudos secundários. Nessa época, as ruas de Paris se animavam por numerosos cantores de rua. Eu adorava ouvi-los: tinha meus cantos preferidos, como a rua do Faubourg Montmartre, a rua Saint-Denis, meu bairro de estudante pobre. Ora, o que percebíamos dessas canções? Éramos quinze ou vinte troca-pernas em trupe ao redor de um cantor. Ouvia-se uma ária, melodia muito simples, para que na última copla pudéssemos retomá-la em coro. Havia um texto, em geral muito fácil, que se podia comprar por alguns roçados, impresso grosseiramente em folhas volantes. Além disso, havia o jogo..$^{32} \mathrm{O}$ que nos havia atraído era o espetáculo. Um espetáculo que me retinha, apesar da hora de meu trem que avançava e me fazia correr em seguida até a Estação do Norte. ${ }^{33}$

O que pode aproximar e/ou distanciar o relato acima das "poéticas da religiosidade dos quintais"?

Paul Zumthor registra o testemunho acima em um dos seus livros. O autor argumenta sobre a performance a partir da voz e do corpo. Dentro do que aqui nos interessa, José Gil pode nos ajudar na compreensão do corpo e da voz no palco de Paul Zumthor. Logo nas primeiras páginas de Escritos Sobre Arte e Artistas ${ }^{34}$, este autor abre um intrigante excurso, com base em seu olhar sobre Hurssel, a respeito dessa questão.

Trago, então, questões, a partir de Gil, que me fazem perguntar sobre o testemunho de Zumthor: será isso o que se chama de presença? Estar em um lugar determinado? Aspectos da fisionomia? Estar de carne e osso?

Mais do que isto, Paul Zumthor nos fala sobre o que o fascina. E porque a fascinação indica uma presença forte, ela nos obriga a interrogarmo-nos sobre esse

\footnotetext{
${ }^{32}$ Grifos meus.

33 Zumthor (2000, p. 33).

${ }^{34}$ GIL, José. Sem Título: escritos sobre arte e artistas. Lisboa: Relógio D’água, 2005.
} 
excesso de presença. Tal fenômeno nasce de signos particulares ou do simples dado irrevogável do que está ali, na rua onde o autor ouvia seus cantos preferidos? Por que Paul Zumthor diz viver dessa lembrança?

Tais interrogações nos fazem pensar, então, sobre a presença da presença, como se através daquela cena representada se tivesse querido obter outra coisa - mesmo que essa coisa reflua sobre a encenação, intensificando sua presença forte.

Supondo então que a fascinação que exerce o cantor de que Paul Zumthor se lembra, ligue-se ao excesso de presença que dela emana, distinguiremos três momentos na sua percepção:

1) o reconhecimento da cena de uma voz com características visíveis determinadas:

\begin{abstract}
Havia o homem, o camelô, sua parlapatice, porque ele vendia as canções, apregoava e passava o chapéu; as folhas-volantes em bagunça num guarda-chuva emborcado na beira da calçada. Havia o grupo, o riso das meninas, sobretudo no fim da tarde, na hora em que as vendedoras saíam de suas lojas, a rua em volta, os barulhos do mundo e, por cima, o céu de Paris que, no começo do inverno, sob as nuvens de neve, se tornava violenta. Mais ou menos tudo isto fazia parte da canção. Era a canção. ${ }^{35}$
\end{abstract}

2) o quase concomitante impacto sobre o olhar, do excesso de presença: não é apenas a percepção de um espetáculo que está ali, mas a extraordinária penetração da presença das vozes; mais, a presença que se impõe excede o conjunto da representação.

3) De tal modo que esse excesso, que vai para além da imagem do espetáculo que o habita por inteiro do interior, agora é toda a presença daqueles elementos triviais, descritos acima (homem, camelô, o grupo das meninas, os barulhos do mundo, o céu de Paris etc.), que se encontra como que acrescida de substância perceptiva e singular.

Caracterizemos melhor este jogo complexo de impregnações entre os dois tipos de presença: o do excesso, para além das formas; e o das formas triviais visíveis.

\footnotetext{
${ }^{35}$ Zumthor (2000, p. 33).
} 
Primeiro, o que significa um excesso de presença para lá do visível? Que o visível, o dado, se prolonga além dos seus próprios contornos, sob um regime particular do invisível. Se considerarmos o segundo momento, em que o olhar sofre o impacto do excesso de presença, sentiremos, por um mísero instante, a fratura entre a cena visível e o que a excede. Qualquer coisa a mais emana desse palco que Zumthor nos apresenta, e não apenas das vozes ou de parte das vozes do atores, ao centro do palco.

Esse "qualquer coisa a mais" perturba, porque não está localizado: em vão, Zumthor o procura na lembrança, ou mesmo ao cantar a melodia. Está fora das formas, impõe-se como um vento mais forte que agitasse o olhar impedindo-o de fixá-lo:

Seja porque não se pode esquecer, por mais que se queira. Seja porque o que foi vivido está incompleto como significado da vida e, embora ela tenha seguido adiante, é preciso o tempo todo estar voltando do presente para trás, porque cada coisa de agora sente a falta de outras de outrora para ser compreendida. Para ser re.sentida: sentimento, sentido. Mas pode ser porque sempre o melhor amor, o melhor do amor, é o que viveu em um outro tempo, quando então... ${ }^{36}$

Essa "qualquer coisa" que foi percebida, que desloca o olhar das formas e o move em direção precisa, é quase caótica. Mas logo depois, e sem que se saiba como nem por que, o excesso de presença, percebido autonomamente, reinveste as formas visíveis.

O que foi que assim reinvestiu, penetrou, se moldou à, e intensificou a encenação? Como caracterizar a presença invisível que apareceu como um excesso relativamente ao cantor, à canção, à voz, ao perceptível ali “em carne e osso”?

O que eu tinha então percebido, sem ter a possibilidade intelectual de analisar era, no sentido pleno da palavra, uma "forma": não fixa nem estável, uma forma-força, um dinamismo formalizado; uma forma finalizadora, se assim eu puder traduzir a expressão alemã de Max Luthi, quando ele fala, a propósito de contos, de Zielform: não um esquema que se soubesse a um assunto, porque a forma não é regida pela regra, ela é

\footnotetext{
${ }^{36}$ Brandão (1998, p. 113).
} 
a regra. Uma regra a todo instante recriada, existindo apenas na paixão ${ }^{37}$ do homem que, a todo instante, adere a ela, num encontro luminoso. ${ }^{38}$

Zumthor chama, então, a esse excesso de presença determinado, forma de uma força: porque é uma força, mas singular; tem forma, mas não figurável de maneira visível.

É como quando queremos descrever o tipo de influência produzida pela presença de alguém e dizemos que ele "é uma forte personalidade", ou que tem "um caráter agressivo", ou pelo contrário “doce”, ou "fugidio", etc. Utiliza-se, nesses casos, uma linguagem de forças, adjetivam-se as formas com as forças expressas. A forma da força não é visível, não está figurada, não é uma pura qualitas nem um puro quantum: é uma grandeza intensiva que surge com uma força determinada em movimento. ${ }^{39}$

De toda a obra de arte emanam formas de força. Partindo desse princípio, Paul Zumthor deu atenção à voz na oralidade da cultura medieval. O autor chama a atenção para os valores incomparáveis à voz que só existem ao vivo. Nesse sentido, diz que o estudo dos medievalistas, como é o seu caso, deveria atentar à beleza interior da voz humana. Essa beleza interior pode gerar-se como particular do indivíduo. Mas também é compreendida como histórica e social naquilo que une os seres e, pelo uso que fazemos dela, modula a cultura comum (1993). Assim, o desejo que animava sua prática, como ele deixa claro em seu testemunho acima, vinha-lhe da contemplação da corporeidade da voz viva. O autor argumenta que há algo na voz da ordem da presença, que emana formas de forças. Essa perspectiva da voz como presença percebe a voz em sua dimensão corpórea na materialidade - proximidade física e tangibilidade nas relações porque de toda a obra de arte emanam formas de forças; nas relações de influência, de autoridade, de carisma, de amor, o que se joga antes de mais nada são relações de força através de formas: porque a relação de forças ganha "contornos" e "figuras". Entre o comportamento moldado por formas e códigos verbais e a violência nua que visa a ruptura da relação,

\footnotetext{
${ }^{37}$ Grifos meus.

${ }^{38}$ Zumthor (2000, p. 33).

${ }^{39}$ Gil (2005, p. 54/55).
} 
existe uma camada não visível de laços em constante movimento que se constroem graças a formas e forças. É mais do que uma relação de forças ${ }^{40}$.

Gil (2005) nos explica quando estamos diante de mais do que uma relação de forças, trazendo o exemplo de uma relação hierárquica qualquer entre um médico e uma enfermeira, por exemplo, a relação estável não é "de forças", mas de dupla captação de formas e forças receptivas.

\begin{abstract}
"Por intuição", diz-se, "por instinto", sabe-se imediatamente como reagir face ao outro, responder às suas exigências, negar-lhes ou substituí-las, etc., etc. Tudo isto porque duas formas de forças se ajustam, se conjugam, se adequam sempre em equilíbrio instável ou metastável, quer dizer, sempre em movimento. ${ }^{41}$
\end{abstract}

O que é particular na obra de arte, e particularmente na voz como presença que Zumthor evoca, é o inesgotável das forças e, assim, a constante intensidade da forma das forças. Constância que não implica imobilidade, mas dinamismo incessante: a força da presença renova-se a cada instante, talvez "com modulações ínfimas de intensidade (o que depende também da subjetividade do espectador)" ${ }^{42}$. Aliada a essa presença que é movente, nunca pode ser permanente, uma presença na qual não podemos nos apoiar, está o que Zumthor chamou performance - "momento privilegiado da 'recepção' -, aquele em que um enunciado é realmente recebido."43 Mas, Paul Zumthor alerta que nem tudo está dito nesta exposição:

A presentificação performancial de um enunciador e de seus ouvintes implica uma mediação que (na acepção corrente da palavra performance) é vocal. Assim, não me contento em remeter ao que designa o termo banalizado oralidade (o fato bruto de que o meio não é a escrita e provoca uma percepção auditiva). Falo de vocalidade, evocando através disto uma operação não neutra, veículo de valores próprios, e produtora de emoções que envolvem a plena corporeidade dos participantes. Pouco importa o estatuto do texto comunicado, seja

\footnotetext{
40 Ibidem, p. 55.

${ }^{41}$ Ibidem.

42 Ibidem.

${ }^{43}$ ZUMTHOR, Paul (2005, p. 141).
} 
ele preparado ou improvisado, fixado ou não por uma escrita anterior. Disso tudo eu só retenho que, num instante determinado, este texto foi transmitido por uma voz humana e que (mesmo que ele fosse, por outro lado, objeto de cem leituras solitárias, puramente visuais) este exato instante o transformou em um momento incomparável, porque único.

Em sua grande obra, Zumthor compreende texto como inacabamento, que vai além dos signos verbais, apresenta-se como interatividade e como signo cultural da diversidade. O texto, agora, não se limita mais a uma sequência fechada de elementos linguísticos, tende para imagem do tecido cultural constituído por múltiplas escrituras em constante movimento. O texto é signo. É nessa interação entre texto e voz que Zumthor, ao conjugar, tão intimamente meios de comunicação de massa e formas poéticas medievais, a partir da teatralidade e da voz nos espaços de comunicação, mostra que, embora distantes no tempo, a experiência contemporânea e medieval destacam a necessidade de algo vivo que movimente o texto para a recepção. É assim que Zumthor nos toca ao esclarecer: "através da voz, a palavra se torna algo exibido e doado, virtualmente erotizado, e também um ato de agressão, uma vontade de conquistar o outro, que a ela se submete, pelo prazer de ouvir"44. O jogo? Porque, para Zumthor, “fazer ouvir" não se trata nem do ouvido, nem do som, ou seja, "fazer ouvir" está sempre no campo do outro, é de lá que a voz provém.

Em Zumthor, o texto é o lugar em que a voz se mostra, em que a voz apresenta-se como um querer dizer da enunciação que jamais se esgota ao término do enunciado. 0 texto é o lugar do dialogismo, do plurilinguismo, do confronto e da atividade tradutória em que o dito e o tom ${ }^{45}$ podem dar margem a muitas possibilidades de discussões de sentido. Nesse contexto, as civilizações e as épocas não passam de tradutores, de intérpretes. A tradição é um movimento de tradução:

Tradução-tradição: a existência de uma cultura na história é incessante tradução dela mesma por ela mesma, com a inevitável derivação que ela carrega consigo. Porque a tradução mais que a tradição não possui

\footnotetext{
${ }^{44}$ Id. A permanência da Voz. Correio da Unesco, no. 10, outubro, 1993, p. 08.

$45 \mathrm{O}$ tom não no sentido exato de tonalidade vocal, mas como uma parte significante para além da significação que o tom pode apresentar, muitas vezes até contrariando o dito (GONÇALVES, 2001, p. 76).
} 
critério... cada frase se questiona em seus fundamentos, se inquieta: não vê subitamente o porto de onde partiu, nem aquele em direção ao qual cinge... nessa navegação sem bússola e propriamente falando interminável. ${ }^{46}$

Assim, Paul Zumthor ressalta a extraordinária potencialidade dos textos nas culturas para constituir-se como testemunho - não pela fidelidade da representação, é evidente, mas pela capacidade de fazer repetir, incessantemente, a voz testemunhal esta presença ausência que por estar em constante devir, como diria Deleuze (2007), de quem Zumthor foi leitor, "não é um órgão nem uma função orgânica; é antes um material, isto é, um conjunto de elementos que varia de acordo com suas conexões, suas relações de movimento e repouso, os diversos agenciamentos individuados onde ele entra." 47 Essa afirmação exige reconsiderarmos todo um estoque de reflexões que se dedica a opor ou hierarquizar o valor da escrita e o valor da voz para o texto nas culturas, para compreender como Zumthor que a grandeza da escrita, sem dúvida, está em integrar o valor da voz. São a voz e o gesto que propiciam uma verdade; eles é que persuadem. As frases sucessivas que são lançadas pela voz, e que parecem unidas somente por sua conexão, entram progressivamente no fio da escuta, em relação mútua de coesão. A coerência última conseguida pela obra é um dom do corpo. ${ }^{48}$

\section{Considerações: imaginando outras conversas}

Neste texto, destaco a performance e a religiosidade do Catumbi a partir da sabedoria coletiva fora do estar que a todos é comum - as poéticas da religiosidade dos quintais no contexto moçambicano e afro-brasileiro de Santa Catarina. Assim, busco colocar em movimento uma possibilidade de produção de sentido sobre a arte que emerge e constitui uma performance negra nas "brincadeiras de negro", como o Catumbi. Para isso, defendo o Catumbi como religião e não como folclore, como quiseram

\footnotetext{
${ }^{46}$ Zumthor (1993, p. 205).

${ }^{47}$ Deleuze (2007, p. 41).

${ }^{48}$ Zumthor (1993, p. 165).
} 
pesquisadores, especialmente em comunidades afro-brasileiras, conforme registra Silva (2015).

Paul Zumthor se constitui como um importante participante deste diálogo porque concebe a performance não somente como representação cênica, mas como o momento em que o enunciado é realmente recebido. E esse enunciado tem como seu principal elemento a poesia: "uma pulsão do ser da linguagem" que só pode existir na "voz viva" na qual "o pensamento é cantado". Assim, defendo que na performance da poética da religiosidade dos quintais há a possibilidade de diálogo com o passado, a transmissão de experiência memorial, de um saber ancestral, anterior, cuja concretização se dá, primeiramente na voz como canção.

Em práticas da religiosidade dos quintais como o Catumbi, é na canção que o passado vê-se capturado. E no ritmo: "lugar onde a escuta se dá", que o saber modelado pelo tempo, como tradição, pode vir a ser de acesso e uso pleno e comum. Nas poéticas das religiosidades dos quintais a performance negra se constitui na canção como poética original, principalmente porque representa em seu surgimento, uma função rememorativa, cujo efeito se faz na presença, uma perspectiva da voz em sua dimensão corpórea na materialidade - proximidade física: o corpo a corpo e tangibilidade das relações. É da importância que Zumthor dá ao aspecto das emoções que envolvem a plena corporeidade dos participantes em práticas como a do Catumbi que o autor renega a concepção de oralidade para instituir a concepção de vocalidade.

Ao finalizar, poderia, então, perguntar: de que maneira a reflexão sobre a dimensão expressiva de práticas como a do Catumbi serve para desenvolver o pensamento e o combate à "ideologia da desqualificação" das práticas afro-brasileiras? O encontro com os "quintais moçambicanos", a partir do reconhecimento de nossas vocalidades, histórias, danças, canções, religião, saberes tradicionais mostram o quanto as práticas afro-brasileiras têm influência das negras vozes que vieram da Terra-mãe. No entanto, como esperar tal reconhecimento se a maioria das comunidades afrodescendentes, herdeiras de alguma prática tradicional, como é o caso do Cacumbi, têm sido empurradas de seus territórios - consequência de um processo de exclusão de longa duração histórica, instituído pelo Projeto da Modernidade? Assim sendo, não 
poderia ser a confrontação ao Projeto - cuja finalidade é desmontar a diversidade - um dos desafios contemporâneos?

\section{Referências}

ALVES, Jucélia Maria; LIMA, Rose Mery de; ALBUQUERQUE, Cleidi (Orgs.). Cacumbi: um aspecto da cultura negra em Santa Catarina. Florianópolis: ufsc: Secretaria da Cultura e do Esporte de Santa Catarina, 1990.

AVIZ, Roselete Fagundes. Khilá: (des)encontros da voz na travessia Brasil-Moçambique. 2012. Tese (Doutorado em Educação) - Universidade Federal de Santa Catarina. Florianópolis, 2012.

AVIZ, Roselete Fagundes. As negras vozes dos quintais: acordes da canção MoçambiqueBrasil. In: MEDEIROS, Fábio Henrique Nunes; MORAES, Taíza Mara Ruen de. Contação de histórias: tradição, poéticas e interfaces. São Paulo: SESC, 2016.

BRANDÃO, Carlos Rodrigues. Memória sertão: cenários, cenas, pessoas e gestos nos sertões de João Guimarães Rosa e de Manuelzão. São Paulo: UNIUBE, 1998.

GIL, José. Sem título: escritos sobre arte e artistas. 2a . ed. Lisboa: Relógio d’água, 2005.

DELEUZE, Gilles. GUATTARI, Félix. Mil platôs: capitalismo e esquizofrenia. Vol. 1 Trad. Ana Lúcia de Oliveira. São Paulo: Ed. 34, 2007.

Gonçalves, Luciana Affonso. A voz na psicanálise: um sopro de vida. Rio de Janeiro: Entreletras, 2001.

LEITE, Ilka Boaventura. Negros no Sul do Brasil: invisibilidade e territorialidade. Florianópolis: Letras Contemporâneas, 1996.

LIGIÉRO, Zeca. Corpo a corpo: estudo das performances brasileiras. Rio de Janeiro: Garamond, 2011.

LOPES, Nei. Prefácio. In: LIGIÉRO, Zeca. Corpo a corpo: estudo das performances brasileiras. Rio de Janeiro: Garamond, 2011.

LOPES, Nei. Prefácio. Enciclopédia brasileira da diáspora africana. São Paulo: Selo Negro, 2004. p. 412. 
MESCHONNIC, Henri. Linguagem, ritmo e vida. Belo Horizonte: Fale: Ed. UFMG, 2006.

MORAIS FILHO, José Alexandre Mello. Festas e tradições populares do Brasil. Rio de Janeiro: F. Briguiet \& Cia., 1946.

MORAES FILHO, Mello. Festas e tradições populares do Brasil. Brasília: Senado Federal 2002, 385 p. (Coleção Biblioteca Básica brasileira),

ROVAI, Marta Gouveia de Oliveira. Mulheres mestres: o papel feminino na organização religiosa e na visibilidade da comunidade congadeira no sul de Minas Gerais. Anais do XIII Encontro Nacional de História Oral. Porto Alegre: ABHO, 2016.

SILVA, Jaime José dos Santos. Memórias do Cacumbi: Cultura afro-brasileira em Santa Catarina, século XIX e XX. 2015. Dissertação (Mestrado em História) - UFSC, Florianópolis, 2015.

SITOE, Bento. Dicionário changana-português. Maputo: Ed. INDE, 1996.

SANTOS, Boaventura de Sousa (Org.). Reconhecer para libertar: os caminhos do Cosmopolitismo Multicultural. Rio de Janeiro: Civilização Brasileira, 2003.

SANTOS, Boaventura de Sousa; MENESES, Maria Paula (Orgs.). Epistemologias do Sul. Coimbra, Portugal: Edições Almedina, 2009.

SODRÉ, Muniz. A verdade seduzida. Rio de Janeiro: Codecri, 1983.

SOUZA, Marina de Mello e. Batalhas rituais centro-africanas e catolicismo negro no Brasil. In: Arnaldo Érico Huff Júnior; Elisa Rodrigues. (Org.). Experiências e interpretações do sagrado.. 1ed.São Paulo: Paulinas; ABHR, 2012, v. , p. 207-223.

ZUMTHOR, Paul. A letra e a voz: a "literatura" medieal. Trad. Amalio Pinheiro, Jerusa Pires Ferreira. São Paulo: Cia das Letras, 1993.

ZUMTHOR, Paul. Presença da Voz. In: ZUMTHOR, Paul. Escritura e Nomadismo: entrevistas e ensaios. Trad. Jereusa Pires Ferreira, Sônia Queiroz. Cotia. SP: Ateliê Editorial. 2005.

ZUMTHOR, Paul. Performance, recepção e leitura. Tradução de Jerusa Pires Ferreira e Suely Fenerich. São Paulo: EDUC, 2000. 
"Brincadeiras de negros": religiosidade e performance nas práticas do Cacumbi em comunidades afrobrasileiras

Roselete Fagundes de Aviz

Recebido em: 08/12/2017

Aprovado 14/04/2018

Universidade do Estado de Santa Catarina - UDESC

Centro de Ciências Humanas e da Educação - FAED

Revista PerCursos

Volume 19 - Número 39 - Ano 2018 revistapercursos@gmail.com 